\title{
Estimation of circulating bovine leukemia virus levels using conventional blood cell counts
}

\author{
S. Nakada, ${ }^{*} \dagger$ J. Kohara, $\ddagger$ and K. Makita ${ }^{1}$ \\ *Hokkaido Higashi Agriculture Mutual Aid Association, 14-37-3 Tawarabashi, Nakashibetsu, Hokkaido, 086-1137, Japan \\ †Veterinary Epidemiology Unit, Graduate School of Veterinary Medicine, Rakuno Gakuen University, 582 Bunkyodai Midorimachi, \\ Ebetsu, Hokkaido, 069-8501, Japan \\ †Animal Research Center of Hokkaido Research Organization, 5-39 Shintoku, Hokkaido, 081-0038, Japan
}

\section{ABSTRACT}

Bovine leukemia virus (BLV) is widely prevalent in Japanese dairy farms. To control BLV infections in Japan, segregating or managing cows according to their proviral load (PVL) is a rational strategy. This study was conducted to establish a quantitative procedure for estimating blood PVL per microliter using a statistical model to offer a cost-effective alternative to the conventional quantitative real-time PCR method. In total, 250 Holstein cows infected with BLV were identified from 10 commercial dairy farms. Information on age was collected and blood samples were tested for white blood cell and lymphocyte counts and PVL using PCR. Generalized linear models with quasi-Poisson errors were used to estimate PVL by selecting age, logarithm of lymphocyte count, and their interaction term as explanatory variables. To evaluate the model, blood samples of $92 \mathrm{BLV}$-infected Holstein cows from 2 other commercial dairy farms were tested, and measured PVL values were compared with estimated PVL values by the model. The logPVL per microliter was modeled by positive associations with log lymphocyte count and age and a negative association with the interaction term. In the evaluation, measured PVL values had a strong correlation with estimated PVL values (Spearman's $\rho=0.87)$. In conclusion, our model provides a cost-effective and more rapid alternative to the conventional method to facilitate test and segregation or management of BLV-suspected cows.

Key words: bovine leukemia virus, proviral load, statistical model, dairy cow

\section{INTRODUCTION}

Bovine leukemia virus (BLV) induces enzootic bovine leukosis (EBL) in cattle (OIE, 2012). There are

\footnotetext{
Received February 18, 2018.

Accepted August 16, 2018.

${ }^{1}$ Corresponding author: kmakita@rakuno.ac.jp
}

3 disease stages of EBL: asymptomatic or aleukemic stage (AL), persistent lymphocytosis (PL), and leukemia or lymphoma (Frie and Coussens, 2015). The BLV infection is a global health problem in cattle that is responsible for significant financial losses in the dairy industry (Bartlett et al., 2014).

Several western European countries with a low prevalence of BLV infection have achieved elimination of BLV infection through national control campaigns using a test and eliminate strategy (Nuotio et al., 2003; Rodríguez et al., 2011). In contrast, the prevalence of BLV infection is high in Argentina (Gutiérrez et al., 2012), Canada (Nekouei et al., 2015), Japan (Murakami et al., 2013), and the United States (USDA, 2007), all of which do not have financial compensation policies for the disease (Rodríguez et al., 2011). In Japan, bovine leukosis is a notifiable disease and has been subject to passive surveillance since 1997 (Murakami et al., 2013). Since then, the number of bovine leukosis cases has continued to increase annually (Murakami et al., 2013; MAFF, 2016). In the latest epidemiology investigation, the seroprevalence of BLV infection for dairy cattle was $40.9 \%(95 \% \mathrm{CI}=40.4-41.4 ; \mathrm{Mu}-$ rakami et al., 2013); therefore, in 2015, the Ministry of Agriculture, Forestry, and Fisheries of Japan published Guidelines for Biosecurity Measures of Enzootic Bovine Leukosis (MAFF, 2015). In these guidelines, the test and segregate or test and manage strategy is recommended, and diagnostic methodologies such as ELISA, qualitative PCR, and quantitative real-time PCR were introduced; however, methodologies to follow were not strictly specified. Real-time PCR and ELISA are widely used in Japan to identify BLV-infected dairy cattle (Nishiike et al., 2016). The test and segregate or test and manage strategy has been practiced in Argentina as well (Gutiérrez et al., 2011, 2012; Alvarez et al., 2013). Quantitative real-time PCR has been used to determine proviral load (PVL) in Japan (Jimba et al., 2010; Jimba et al., 2012), and BLV-infected cows with PL have been shown to have significantly higher PVL than AL cows (Ohno et al., 2015). Some 
groups suggested that cattle with high PVL are efficient transmitters (Gutiérrez et al., 2014; Ohno et al., 2015). Although advantages to using real-time PCR exist, this technique has not been used in Japan as a uniformed routine tool in the national control program because of the high cost and complex equipment required (Nishiike et al., 2016).

Researchers have proposed several alternative methods to the quantitative real-time PCR method. Serological studies suggested that antibody titer against BLVgp51, the main antigenic glycoprotein of the viral envelope, is useful in the detection of BLV-infected cattle including nonlymphocytotic ones, whereas antiBLVp24 antibody titer correlates with PVL regardless the status of lymphocytosis, suggesting it is potentially useful as a detection tool for efficient transmitters (Juliarena et al., 2007; Gutiérrez et al., 2012). However, these studies quantified PVL per a volume of DNA, not the level of PVL per a unit volume of blood. Moreover, Jimba et al. (2012) suggested only partial correlation between PVL per 100,000 peripheral white blood cells measured using real-time PCR and serological results. A hematological approach showed that white blood cell count was correlated with blood PVL and can be a good monitoring tool (Alvarez et al., 2013).

Although previous studies proposed less-expensive and more-convenient alternatives to the quantitative real-time PCR method, they have not achieved in estimation of the level of PVL per a unit volume of blood. Therefore, our study was conducted to establish a quantitative procedure for estimating blood PVL per microliter in BLV-infected dairy cattle using a statistical model based on conventional blood cell counts and cow age to offer a cost-effective alternative to the quantitative real-time PCR method.

\section{MATERIALS AND METHODS}

\section{Study Design}

Our study consisted of 3 steps. First, the statistical relationship between blood lymphocyte count (Lym) and age among BLV-noninfected cattle was studied as a baseline. Second, the statistical model to estimate blood PVL per microliter was established using BLV-infected cows. Third, verification of this statistical model was conducted using cows in the other farms.

\section{Study Areas and Farm and Cow Selection}

For the baseline survey on the relationship between Lym and age, 444 BLV-noninfected Holstein cows were studied from purposively selected 5 dairy farms in the Tokachi and Kushiro regions of Hokkaido, Japan. These 5 farms included a BLV-free farm and 4 farms known to have infected cows.

For the establishment of a statistical model, a total of 250 Holstein cows infected with BLV from 10 commercial dairy farms within the Nemuro and Kushiro regions of Hokkaido, Japan, were intentionally selected. One of these 10 farms participated in the baseline survey mentioned above. Table 1 shows the numbers of infected cows studied and previous BLV test results based on either PCR or ELISA in these farms. Of the 10 farms, 8 used tiestalls and 1 used freestalls. The remaining farm had both tie- and freestalls. The farm size ranged between 54 and 284 cows, with a median of 141 cows. These cows were between 0.5 and 14 yr old and apparently healthy, without any clinical signs of EBL. The within-farm prevalence of BLV on 10 farms ranged between 7.5 and $43.7 \%$, and overall animal-level prevalence was $25.8 \%$. To evaluate the predictability of

Table 1. Numbers of infected cows with bovine leukemia virus (BLV) studied and previous BLV test results in the 10 dairy farms in Nemuro and Kushiro regions in Hokkaido, Japan

\begin{tabular}{|c|c|c|c|c|c|}
\hline Farm & Stall & $\begin{array}{l}\text { Number } \\
\text { of cows }\end{array}$ & $\begin{array}{c}\text { Previous } \\
\text { prevalence }^{1}(\%)\end{array}$ & Diagnosis used ${ }^{1}$ & $\begin{array}{l}\text { Infected cows } \\
\text { studied }^{2}\end{array}$ \\
\hline A & Tiestall & 84 & 3.0 & PCR & 24 \\
\hline B & Tiestall & 119 & 43.7 & PCR + ELISA & 10 \\
\hline $\mathrm{D}$ & Tiestall & 189 & 20.6 & PCR + ELISA & 21 \\
\hline $\mathrm{E}$ & Free- and tiestalls & 229 & 27.5 & PCR & 40 \\
\hline $\mathrm{F}$ & Tiestall & 103 & 43.7 & PCR & 20 \\
\hline I & Tiestall & 67 & 10.4 & PCR & 7 \\
\hline $\mathrm{J}$ & Tiestall & 54 & 27.8 & ELISA & 13 \\
\hline
\end{tabular}

${ }^{1}$ Initial diagnosis.

${ }^{2}$ Cows whose proviral load was quantified using quantitative real-time PCR method using coordination of common motifs primers for BLV (Riken Genesis, Tokyo, Japan). 
the statistical model, which used the data from above 10 farms, 92 apparently healthy but BLV-infected Holstein cows from 2 commercial dairy farms in the Tokachi region were selected.

\section{Sample Collection}

Owner consent from all selected farms was obtained in advance for collection of blood samples and age information for research purposes. Blood sampling and age information collection were conducted in the above-mentioned 16 farms for all the baseline, model establishment, and evaluation studies between October 2014 and December 2015.

In this study, blood samples were collected by caudal or jugular venipuncture, immediately injected into vacuum blood-collection tubes containing EDTA-2K, and kept in cold storage. The next day, whole blood was brought to the Agricultural Research Department of Hokkaido Research Organization Animal Research Center, where Lym, white blood cell count, and quantification of PVL per cell were assayed.

\section{Blood Lymphocyte Count}

Lymphocyte and white blood cell count were assayed on the same day that samples were received using an automated hematology analyzer (Sysmex XT-2000iV; Sysmex, Hyogo, Japan).

\section{BLV Diagnosis}

Bovine leukemia virus infection status of animals were identified based on either detection of anti-BLV antibody or BLV provirus, as our study was conducted under ordinal veterinary clinical services. Anti-BLVgp51 antibodies were detected using a commercial ELISA kit (JNC Inc., Tokyo, Japan); BLV provirus was detected by nested PCR targeting the BLV long-terminal repeat region, which is described elsewhere (Tajima et al., 2003).

\section{Quantification of BLV PVL}

Genomic DNA was isolated from EDTA-treated whole blood samples using the Wizard Genomic DNA Purification Kit (Promega, Tokyo, Japan) and quantified using the quantitative real-time PCR method using coordination of common motifs primers for BLV (Riken Genesis, Tokyo, Japan). Proviral load per white blood cell was quantified by evaluating the number of copies of BLV long-terminal repeat region gene normalized to that of the bovine leukocyte antigen $D R A$ gene (Jimba et al., 2010). Blood PVL per microliter was quantified by multiplying the PVL per white blood cell and white blood cell count per microliter.

\section{Statistical Analysis}

Data from sampled cows were recorded and handled using commercially available spreadsheet software (Excel 2013; Microsoft Corp., Redmond, WA).

Step 1: Understanding Lym and Age Among $B L V$-Noninfected Cattle. For the baseline data of BLV-noninfected cattle, the relationship between Lym and age of cattle was analyzed using a Poisson regression model in Generalized Linear Model (GLM) framework, with quasi-Poisson errors selecting Lym as an outcome variable and age as an explanatory variable because of the overdispersion of Lym data (Ver Hoef and Boveng, 2007; Crawley, 2013a; Crawley, 2013b).

Step 2: Establishment of a Statistical Model to Estimate the Blood PVL. For the establishment of a statistical model to estimate the blood PVL per microliter, at first correlations between logLym and $\log$ PVL per microliter, logLym and age, and logPVL per microliter and age of BLV-infected cows were tested by Spearman's rank correlation coefficient (Spearman's $\rho)$. Logarithm of Lym and blood PVL per microliter were used because logarithm of a count is known to follow Normal distribution (log-link; Crawley, 2013a), and tests can show more robust results than using the original scale. Second, univariable analyses were performed for BLV-infected cows using Poisson regression models in GLM framework with quasi-Poisson errors, with blood PVL per microliter as an outcome variable and $\log L y m$ and age as explanatory variables. Third, multivariable analysis was performed using a Poisson regression model in GLM framework with quasi-Poisson errors, with blood PVL per microliter as an outcome variable and $\log L y m$, age, and their interaction as explanatory variables.

Step 3: Evaluation of Predictability of the Statistical Model. To evaluate the predictability of the statistical model, the correlation between the measured blood PVL per microliter and blood PVL per microliter estimated by the statistical model was tested using Spearman's rank correlation coefficient. In addition, although blood PVL per microliter does not follow Normal distribution, linear regression was performed to show the predictability of the proposed statistical model. Moreover, Spearman's rank correlation tests were performed between $\log \mathrm{PVL}$ per cell and log of white blood cell count, as well as between logPVL per 


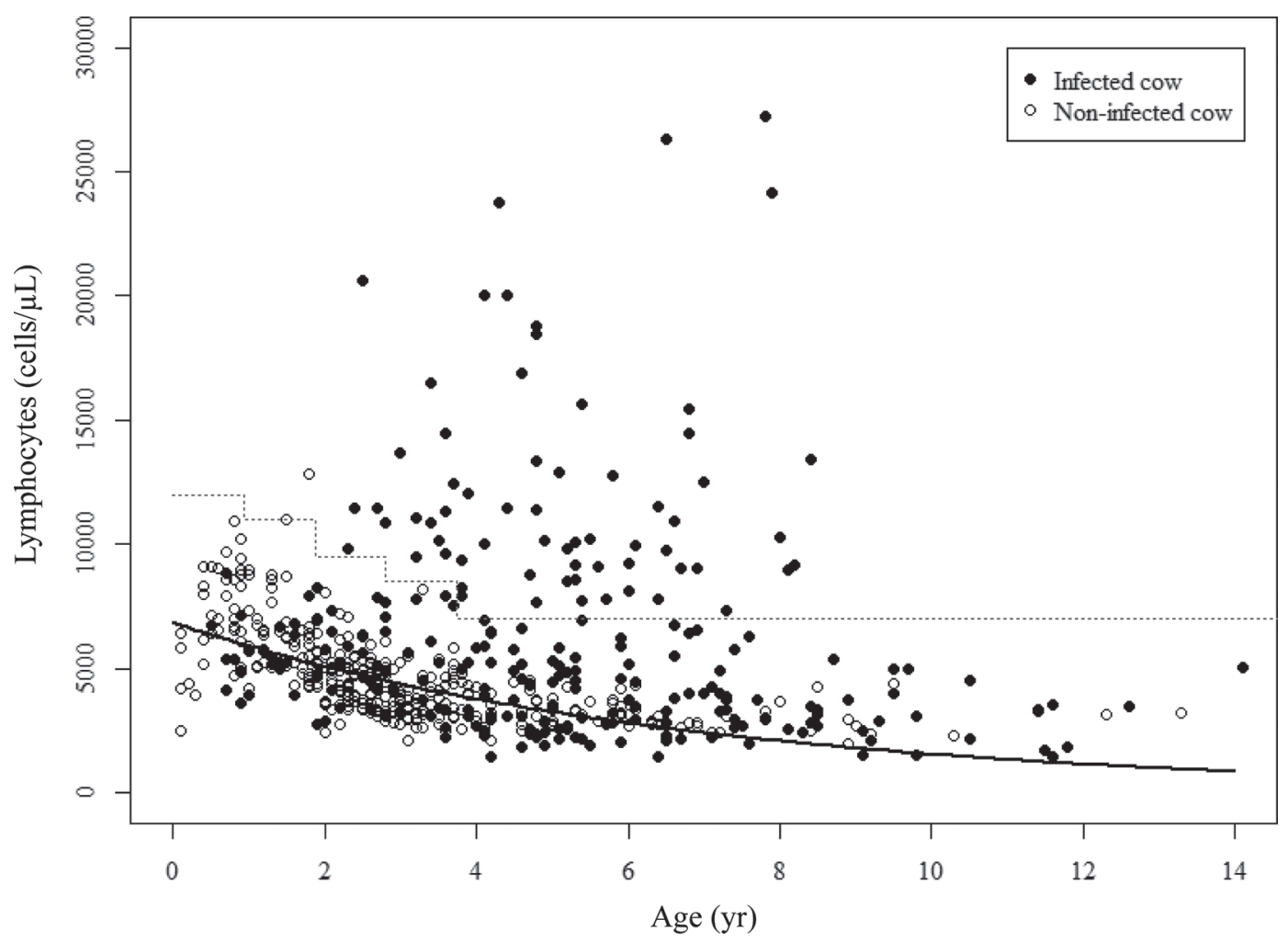

Figure 1. Scatter plot showing the relationships between blood lymphocyte count and age of cows infected with bovine leukemia virus or not. A solid line shows predicted line by the model for noninfected cows and the dotted line is the European Community's Leukosis Key.

cell and age, to explain the model predictability. All statistical analyses were performed using $\mathrm{R}$ version 3.2 .2 (R Core Team, 2015).

\section{RESULTS}

\section{Descriptive Statistics}

For BLV-noninfected cows, the median and mean age were 2.60 and $2.96 \mathrm{yr}$ (2.5 and 97.5 percentiles $=0.50$, 7.99), and the median and mean Lym were 4,035.0 and $4,421.0$ cells $/ \mu \mathrm{L}$ of blood $(2.5$ and 97.5 percentiles $=$ $2,150.8,8,809.3)$, respectively. In contrast, the median and mean age of BLV-infected cows studied were 4.88 and $5.10 \mathrm{yr}(2.5$ and 97.5 percentiles $=0.90,11.38)$ and the median and mean Lym of these cows were 5,075.0 and $6,328.5$ cells $/ \mu \mathrm{L}$ of blood (2.5 and 97.5 percentiles $=1,826.8,19,755.5)$, respectively.

The median and mean blood PVL of BLV-infected cows were $2,274.2$ and $5,020.9$ copies/ $\mu \mathrm{L}$ (2.5 and 97.5 percentiles $=0.3-25,279.0$ ), respectively. Provirus was detected from all the 154 ELISA-positive samples used for statistical modeling (farms B, C, D, H, and $\mathrm{J}$ in Table 1), except 1 nonlymphocytotic cow diagnosed BLV-positive using both ELISA and nested PCR that had a PVL of 0 copies/ $\mu \mathrm{L}$; this cow was excluded from following statistical analysis due to the contradiction of PCR results.

\section{Relationship Between Lym and Age Among BLV-Noninfected Cows}

Figure 1 shows the relationships between Lym and age among both BLV-infected and uninfected cows. A decline of Lym over age was observed among nonlymphocytotic cows regardless the infection status, and the baseline study GLM result among BLV-noninfected cows showed significant negative linear relationship between logLym and age (slope $=-0.16, \mathrm{SE}=0.01$, $P<0.01)$.

\section{Prediction Model}

As shown in the Figure 1, 28 of 31 BLV-infected cows $(90.3 \%)>8$ yr of age did not have lymphocytosis. These older cows showed a distinct pattern of Lym distribution from the younger cows and were excluded from the analysis. The correlation coefficients $(\rho)$ between age and $\log \mathrm{Lym}$, age and $\log$ blood PVL per microliter, and $\log$ Lym and log blood PVL per microliter were -0.25 
Table 2. The final multivariable Poisson regression model to predict bovine leukemia virus proviral load per microliter using cow's age and logarithm of lymphocyte (logLym) count

\begin{tabular}{lrcc}
\hline Variable & Estimate & $\begin{array}{c}\text { Standard } \\
\text { error }\end{array}$ & $P$-value \\
\hline Intercept & -12.49 & 1.92 & $<0.01$ \\
Age & 1.31 & 0.34 & $<0.01$ \\
logLym & 2.31 & 0.21 & $<0.01$ \\
logLym:Age & -0.14 & 0.04 & $<0.01$ \\
\hline
\end{tabular}

$(P<0.01),-0.02(P=0.78)$, and $0.84(P<0.01)$, respectively. These data suggested significant correlations between logLym and age as well as logLym and log blood PVL per microliter in BLV-infected cows.

Univariable GLM showed a significant linear relationship between $\log$ PVL per microliter and logLym (slope $=0.84, \mathrm{SE}=0.03, P<0.01$ ), but not between $\log \mathrm{PVL}$ per microliter and age (slope $=0.11, \mathrm{SE}=$ $0.06, P=0.11$ ). Table 2 shows the multivariable model result. Age, logLym, and their interaction term were significant $(P<0.01)$ and the model was defined as equation 1; the overdispersion parameter was 1921.5:

$$
\begin{aligned}
\log \mathrm{PVL}= & 1.31 \times(\text { age })+2.31 \times(\log \mathrm{Lym})-0.14 \\
& \times(\text { age } \times \log \mathrm{Lym})-12.49 .
\end{aligned}
$$

\section{Evaluation of the Statistical Model}

The median and mean age of cows studied for verification were 4.48 and $4.65 \mathrm{yr}(2.5$ and 97.5 percentiles $=2.15,8.29)$, respectively. The median and mean Lym were 4,665.0 and 6,132.1 cells/ $\mu \mathrm{L}$ of blood (2.5 and 97.5 percentiles $=2,283.8,13,969.3)$, and median and mean PVL were $1,906.4$ and $3,808.2$ copies/ $\mu \mathrm{L}$ of blood $(2.5$ and 97.5 percentiles $=1.5,17,991.1)$, respectively. The data set included 4 cows $>8$ yr of age; therefore, data from the remaining 88 blood samples were included in the evaluation.

The values of blood PVL per microliter quantified by quantitative real-time PCR method using coordination of common motifs primers for BLV and blood PVL per microliter estimated from the statistical model were strongly correlated $(\rho=0.87, P<0.01)$. The linear regression (equation 2), selecting the predicted blood PVL per microliter using equation 1 as an outcome variable, had a significant slope $(P<0.01)$ but was smaller than 1 (slope $=0.74, \mathrm{SE}=0.05$ ). This suggested that predicted blood PVL per microliter tends to be overestimated when actual (measured) blood PVL per microliter is low, whereas it is underestimated when actual blood PVL per microliter is high (Figure 2):

$$
\begin{gathered}
\text { Predicted blood PVL }= \\
0.74 \times(\text { actual blood PVL })+1,686 .
\end{gathered}
$$

Figure 3 shows the relationship between $\log \mathrm{PVL}$ per cell and $\log$ of white blood cell count per microliter, which were strongly correlated $(\rho=0.73, P<0.01)$; PVL per cell was close to 1 among cows with higher white blood cell count (Figure 3). Moreover, logPVL per cell was positively correlated with age $(\rho=0.14, P$ $=0.04$, data not shown in figures).

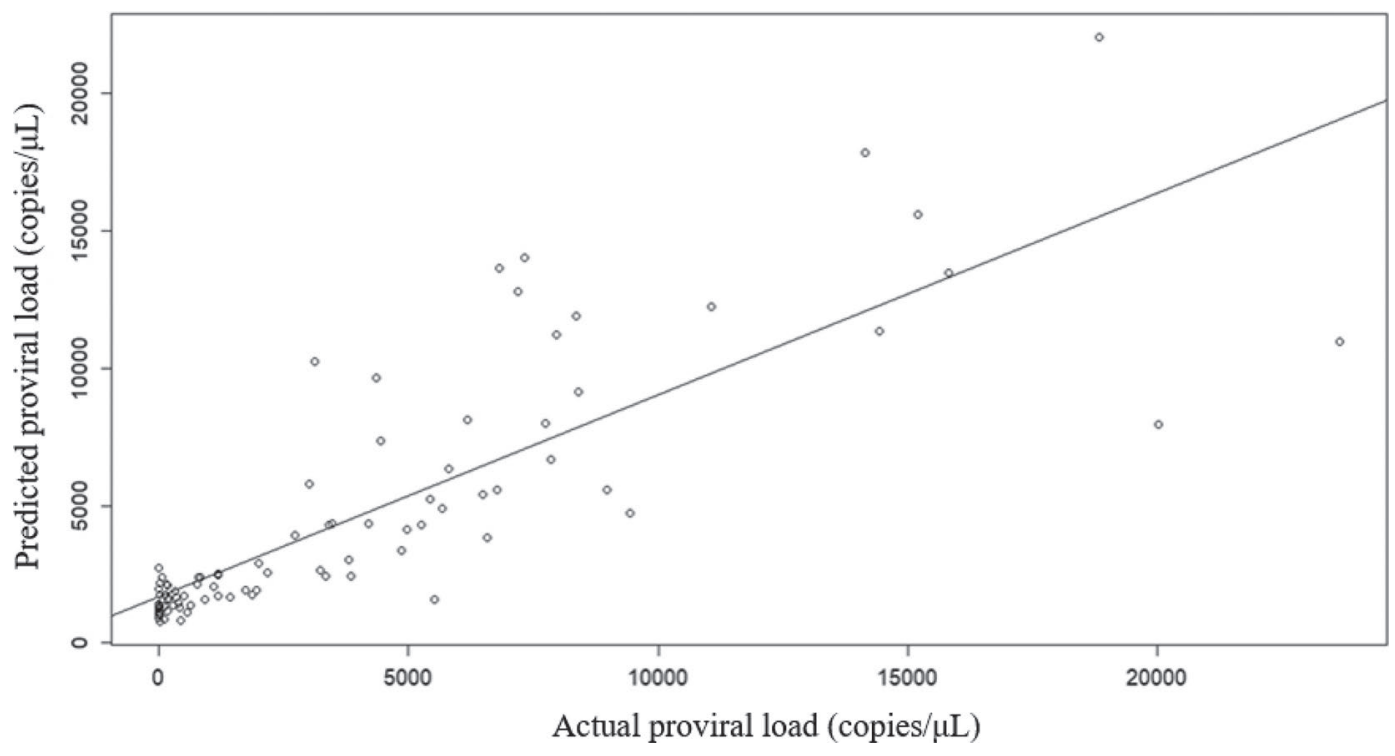

Figure 2. Scatter plot showing the relationship between predicted and actually measured proviral loads with a regression line. 


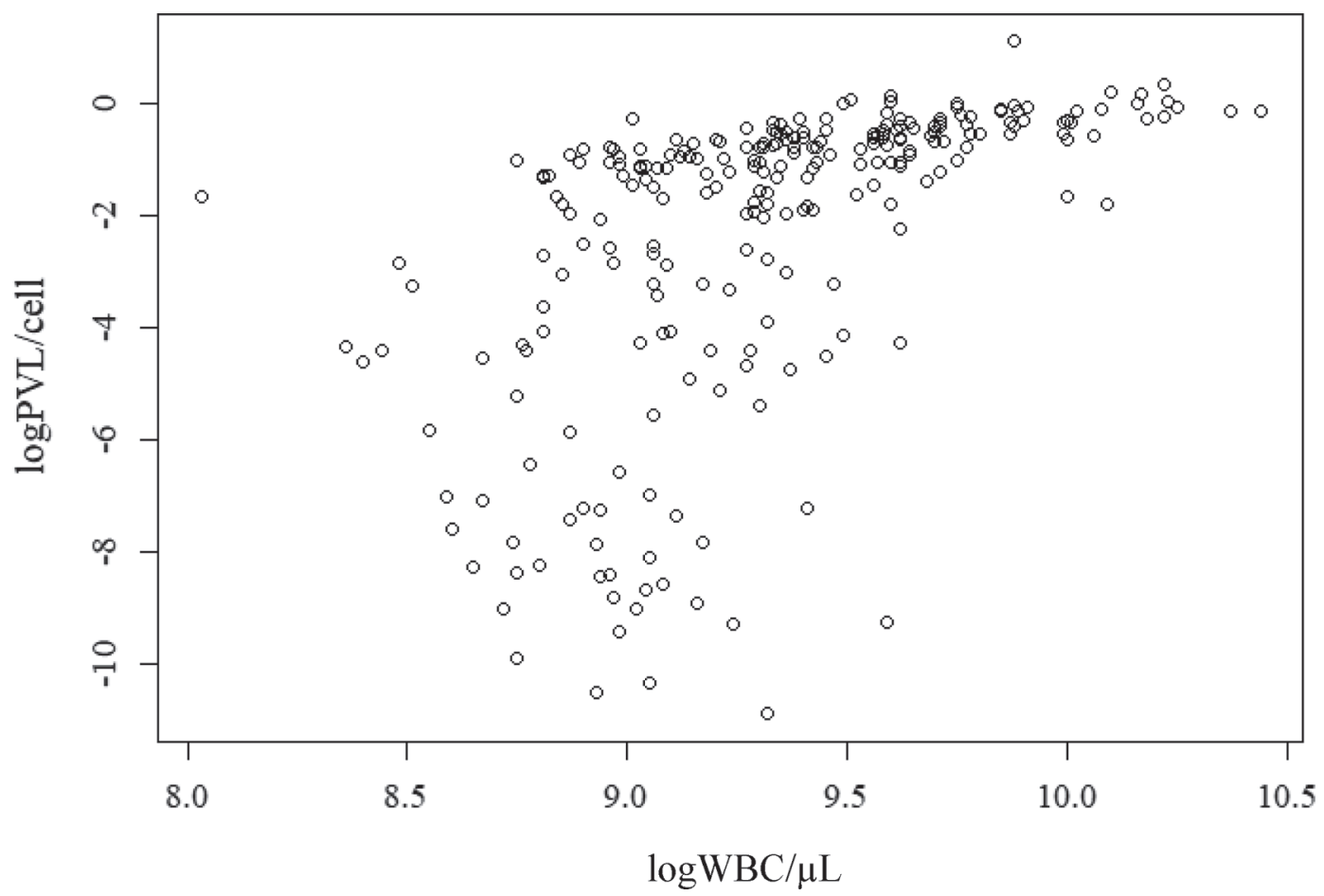

Figure 3. Scatter plot showing the relationship between log proviral load (PVL) per cell and log of white blood cell count (WBC) per microliter.

\section{DISCUSSION}

The measurement of PVL is not widely used in Japan, primarily due to the cost and labor involved to perform real-time PCR. We demonstrated for the first time that a statistical model could be used as a substitute for quantitative real-time PCR.

Our statistical model to estimate PVL consisted of 2 explanatory variables, age and logLym, and their interaction term. A positive relationship between PVL and Lym in BLV-infected cows was previously reported (Ohno et al., 2015); however, a significant association between PVL and age has not been reported in previous studies (Juliarena et al., 2007; Miyasaka et al., 2013; Ohno et al., 2015). Similarly, we found no significant association between blood PVL per microliter and age in the univariable analysis. Two possible reasons exist as to why the statistical model required age. First, as shown in the correlation test result as well as in the GLM for BLV-noninfected cows, Lym decreases as a cow gets older. This aging effect has been reported in the reduction of both Lym (Mekata et al., 2018) and white blood cell count (Roland et al., 2014) among BLV-noninfected cows in the other studies. In our statistical model, the interaction term explains about this relationship. The second reason is the progression of lymphocytosis over age among BLV-infected cows, as BLV infected cows undergo a protracted AL stage with a low PVL that continues for between 1 and 8 yr (Kabeya et al., 2001) and $30 \%$ of BLV-infected cows deteriorate into the PL stage (Kabeya et al., 2001; Frie and Coussens, 2015). Moreover, the European Community's Leukosis Key or Bendixen's key is composed of peripheral blood lymphocyte counts and age (Bendixen, 1960; Nuotio et al., 2003; Acaite et al., 2007; EFSA AHAW Panel, 2015); therefore, the positive relationship between age and blood PVL per microliter in the multivariable model was considered biologically plausible.

Previous research reported that perinatal infection with BLV could quickly lead to high PVL per cell (Gutiérrez et al., 2014). Although Lym is higher at a younger age, as our study showed, the probability of developing lymphocytosis is limited in such age groups; probability of transmission of infection is also determined by the number of infected Lym circulating (Mammerickx et al., 1987; Gutiérrez et al., 2014). Our study used blood PVL per microliter as an outcome variable and young stock were included in the analysis; therefore, our model is applicable to young animals as well. Moreover, particularly high PVL per cell among young stocks were not observed in our study, and the contribution of perinatal infection to disease transmission in an endemic herd may not always be significant.

To demonstrate predictability of our model, we evaluated the model by comparing predicted and actually quantified blood PVL per microliter values using data 
from 2 additional farms not included in the statistical modeling. However, as the slope of regression showed, our model may overestimate blood PVL per microliter when actual blood PVL per microliter is low, whereas it may underestimate blood PVL when actual blood PVL per microliter is high. Additional correlation tests showed that the low provirus productivity of the infected white blood cells among some proportion of nonlymphocytotic cows, particularly younger cows, caused this problem. However, as field veterinarians can send blood samples of potential highly efficient transmitters suggested by our statistical model to the laboratories for confirmation using quantitative PCR, this over- and underestimation problem would not discourage field application. On the other hand, field veterinarians may still need criteria to recommend a laboratory confirmation, such as the European Commission's Leukosis Key, based on our model. In addition, further studies for sensitivity, specificity, and predictive values on such criteria may be needed.

Regarding the representativeness of the 10 commercial dairy farms used in our study, the mean number of dairy farms in the Nemuro region is 135.3 cows (Hokkaido Government Nemuro Subprefectural Bureau, 2017), and studied farms were considered to be representative for the region. The farms used in our study were not randomly sampled, and selection bias due to the influence of established strong relationship between the veterinarians and the farmers on the disease control may have existed. In the BLV-infected farms without a good relationship with a veterinarian, BLV control may be delayed and the proportion of lymphocytotic cows may be higher than the farms controlling BLV infections. The model estimated using data from such farms might show better predictability, as information from lymphocytotic cows would be weighed heavier. Although verification was conducted with 2 additional farms in our study, further studies may be needed for more robust validation.

In our data set, 28 of $32 \mathrm{BLV}$-infected cows $>8 \mathrm{yr}$ of age $(87.5 \%)$ did not develop lymphocytosis. In general, cows of all ages are susceptible to BLV; typically, infected cows $>3$ yr of age develop tumors (lymphosarcomas; OIE, 2012). Recently, genetic resistance to BLV infection was reported and bovine MHC class II BoLA-DRB3.2 allelic diversity was found to be relevant to the progression of BLV infection (van Eijk et al., 1992; Panei et al., 2009; Miyasaka et al., 2013; Nikbakht Brujeni et al., 2016). Therefore, older BLVinfected cows in our study that did not develop lymphocytosis might carry the resistance gene. In terms of the sensitivity of the exclusion of these older cows from statistical modeling, the mean calving number of cows that have been removed from farms in Japan was
4 (Japan Dairy Council, 2012), and our model based on the cows younger than 8 yr old can be generally applicable to Japanese dairy population.

In conclusion, our statistical model for blood PVL per microliter estimation based on Lym and age of BLV-infected cows, accompanied by quantitative PCR for the BLV-suspected cows, can be a useful tool in prioritizing high-risk cows to be removed from dairy herds to facilitate within-herd BLV control. We did not determine whether this statistical model could be applicable for use in BLV-infected beef cattle, and we did not consider the role of genetic resistance to BLV infection. Moreover, cost-effectiveness of the controlling methods applying this model or suitable criteria to recommend for a confirmatory PCR based on the model have not been studied. We will need to examine these issues in the future.

\section{ACKNOWLEDGMENTS}

This study was carried out as research commissioned by the Hokkaido Higashi Agriculture Mutual Aid Association (Nakashibetsu, Hokkaido, Japan) to the Animal Research Center of Hokkaido Research Organization (Shintoku, Hokkaido, Japan). The authors thank the veterinarians of the Hokkaido Higashi Agriculture Mutual Aid Association for collecting blood samples.

\section{REFERENCES}

Acaite, J., V. Tamosiunas, K. Lukauskas, J. Milius, and J. Pieskus. 2007. The eradication experience of enzootic bovine leukosis from Lithuania. Prev. Vet. Med. 82:83-89. https://doi.org/10.1016/j .prevetmed.2007.05.010.

Alvarez, I., G. Gutierrez, M. Gammella, C. Martinez, R. Politzki, C. Gonzalez, L. Caviglia, H. Carignano, N. Fondevila, M. Poli, and K. Trono. 2013. Evaluation of total white blood cell count as a marker for proviral load of bovine leukemia virus in dairy cattle from herds with a high seroprevalence of antibodies against bovine leukemia virus. Am. J. Vet. Res. 74:744-749. https://doi.org/10 .2460 /ajvr.74.5.744.

Bartlett, P. C., L. M. Sordillo, T. M. Byrem, B. Norby, D. L. Grooms, C. L. Swenson, J. Zalucha, and R. J. Erskine. 2014. Options for the control of bovine leukemia virus in dairy cattle. J. Am. Vet. Med. Assoc. 244:914-922. https://doi.org/10.2460/javma.244.8.914.

Bendixen, H. J. 1960. Leucosis in cattle in Denmark. II. Pathogenesis and endemic status. Dtsch. Tierarztl. Wochenschr. 67:57-63.

Crawley, M. J. 2013a. Generalized linear models. Pages 557-578 in The R Book. 2nd ed. John Wiley \& Sons Ltd., West Sussex, UK.

Crawley, M. J. 2013b. Count data. Pages 579-598 in The R Book. 2nd ed. John Wiley \& Sons Ltd., West Sussex, UK.

EFSA AHAW Panel (EFSA Panel on Animal Health and Welfare). 2015. Scientific opinion on enzootic bovine leukosis. EFSA J. 13:4188. https://doi.org/10.2903/j.efsa.2015.4188.

Frie, M. C., and P. M. Coussens. 2015. Bovine leukemia virus: A major silent threat to proper immune responses in cattle. Vet. Immunol. Immunopathol. 163:103-114. https://doi.org/10.1016/j.vetimm .2014.11.014.

Gutiérrez, G., I. Alvarez, R. Merlini, F. Rondelli, and K. Trono. 2014 Dynamics of perinatal bovine leukemia virus infection. BMC Vet. Res. 10:82. https://doi.org/10.1186/1746-6148-10-82. 
Gutiérrez, G., I. Alvarez, R. Politzki, M. Lomónaco, M. J. Dus Santos, F. Rondelli, N. Fondevila, and K. Trono. 2011. Natural progression of bovine leukemia virus infection in Argentinean dairy cattle. Vet. Microbiol. 151:255-263. https://doi.org/10.1016/j.vetmic 2011.03.035.

Gutiérrez, G., H. Carignano, I. Alvarez, C. Martínez, N. Porta, R. Politzki, M. Gammella, M. Lomonaco, N. Fondevila, M. Poli, and K. Trono. 2012. Bovine leukemia virus p24 antibodies reflect blood proviral load. BMC Vet. Res. 8:187. https://doi.org/10.1186/1746 $-6148-8-187$.

Hokkaido Government Nemuro Subprefectural Bureau. 2017. Annual Statistics of Agriculture. Accessed Sep. 5, 2017. http://www .nemuro.pref.hokkaido.lg.jp/ss/num/nemuronougyou.htm.

Japan Dairy Council. 2012. Report of national basic survey of dairy industry in 2011. Accessed Sep. 5, 2017. http://www.dairy.co.jp/ dairydata/kulbvq0000006r3l-att/kulbvq0000006rq5.pdf.

Jimba, M., S. N. Takeshima, K. Matoba, D. Endoh, and Y. Aida. 2010. BLV-CoCoMo-qPCR: Quantitation of bovine leukemia virus proviral load using the CoCoMo algorithm. Retrovirology 7:91. https: //doi.org/10.1186/1742-4690-7-91.

Jimba, M., S. N. Takeshima, H. Murakami, J. Kohara, N. Kobayashi, T. Matsuhashi, T. Ohmori, T. Nunoya, and Y. Aida. 2012. BLVCoCoMo-qPCR: A useful tool for evaluating bovine leukemia virus infection status. BMC Vet. Res. 8:167. https://doi.org/10.1186/ 1746-6148-8-167.

Juliarena, M. A., S. E. Gutiérrez, and C. Ceriani. 2007. Determination of proviral load in bovine leukemia virus-infected cattle with and without lymphocytosis. Am. J. Vet. Res. 68:1220-1225. https:// doi.org/10.2460/ajvr.68.11.1220.

Kabeya, H., K. Ohashi, and M. Onuma. 2001. Host immune responses in the course of bovine leukemia virus infection. J. Vet. Med. Sci. 63:703-708.

MAFF. 2015. Guidelines for Biosecurity Measures of Enzootic Bovine Leukosis. Accessed Sep. 5, 2017. www.maff.go.jp/j/syouan/douei/ pdf/ebl_guide.pdf.

MAFF. 2016. Annual Statistics of Notifiable Animal Infectious Diseases (1937-2015). Accessed Sep. 5, 2017. http://www.maff.go.jp/ j/syouan/douei/kansi_densen/pdf/h27_todokede_ruinen.pdf.

Mammerickx, M., D. Partetelle, K. de Clercq, and A. Burny. 1987. Experimental transmission of enzootic bovine leucosis to cattle, sheep and goats: Infectious doses of blood and incubation period of the disease. Leuk. Res. 11:353-358.

Mekata, H., M. Yamamoto, Y. Kirino, S. Sekiguchi, S. Konnai, Y. Horii, and J. Norimine. 2018. New hematological key for bovine leukemia virus-infected Japanese Black cattle. J. Vet. Med. Sci. $80: 316-319$.

Miyasaka, T., S. N. Takeshima, M. Jimba, Y. Matsumoto, N. Kobayashi, T. Matsuhashi, H. Sentsui, and Y. Aida. 2013. Identification of bovine leukocyte antigen class II haplotypes associated with variations in bovine leukemia virus proviral load in Japanese Black cattle. Tissue Antigens 81:72-82. https://doi.org/10.1111/ tan. 12041

Murakami, K., S. Kobayashi, M. Konishi, K. Kameyama, and T. Tsutsui. 2013. Nationwide survey of bovine leukemia virus infection among dairy and beef breeding cattle in Japan from 2009-2011. J. Vet. Med. Sci. 75:1123-1126.

Nekouei, O., J. VanLeeuwen, J. Sanchez, D. Kelton, A. Tiwari, and G. Keefe. 2015. Herd-level risk factors for infection with bovine leuke- mia virus in Canadian dairy herds. Prev. Vet. Med. 119:105-113. https://doi.org/10.1016/j.prevetmed.2015.02.025.

Nikbakht Brujeni, G., R. Ghorbanpour, and A. Esmailnejad. 2016. Association of BoLA-DRB3.2 alleles with BLV infection profiles (persistent lymphocytosis/lymphosarcoma) and lymphocyte subsets in Iranian Holstein cattle. Biochem. Genet. 54:194-207. https: //doi.org/10.1007/s10528-016-9712-6.

Nishiike, M., M. Haoka, T. Doi, T. Kohda, and M. Mukamoto. 2016. Development of a preliminary diagnostic measure for bovine leukosis in dairy cows using peripheral white blood cell and lymphocyte counts. J. Vet. Med. Sci. 78:1145-1151. https://doi.org/10.1292/ jvms.16-0022.

Nuotio, L., H. Rusanen, L. Sihvonen, and E. Neuvonen. 2003. Eradication of enzootic bovine leukosis from Finland. Prev. Vet. Med. 59:43-49. https://doi.org/10.1016/S0167-5877(03)00057-6.

Ohno, A.. S. N. Takeshima, Y. Matsumoto, and Y. Aida. 2015. Risk factors associated with increased bovine leukemia virus proviral load in infected cattle in Japan from 2012 to 2014. Virus Res. 210:283-290. https://doi.org/10.1016/j.virusres.2015.08.020.

OIE. 2012. Enzootic bovine leucosis. Chapter 2.4.10 in Manual of Diagnostic Tests and Vaccines for Terrestrial Animals, 7th ed. World Organization for Animal Health (OIE), Paris, France. Accessed Sep. 5, 2017. http://www.oie.int/fileadmin/Home/eng/Health _standards/tahm/2.04.10_EBL.pdf.

Panei, C. J., K. Suzuki, M. G. Echeverria, M. S. Serena, G. E. Metz, and E. T. Gonzalez. 2009. Association of BoLA-DRB3.2 alleles with resistance and susceptibility to persistent lymphocytosis in BLV infected cattle in Argentina. Int. J. Dairy Sci. 4:123-128. https://doi.org/10.3923/ijds.2009.123.128.

R Core Team. 2015. R: A language and environment for statistical computing. R Foundation for Statistical Computing, Vienna, Austria. Accessed Sep. 5, 2017. https://www.R-project.org/.

Rodríguez, S. M., A. Florins, N. Gillet, A. de Brogniez, M. T. SanchezAlcaraz, M. Boxus, F. Boulanger, G. Gutierrez, K. Trono, I. Alvarez, L. Vagnoni, and L. Willems. 2011. Preventive and therapeutic strategies for bovine leukemia virus: lessons for HTLV. Viruses 3:1210-1248. https://doi.org/10.3390/v3071210.

Roland, L., M. Drillich, and M. Iwersen. 2014. Hematology as a diagnostic tool in bovine medicine. J. Vet. Diagn. Invest. 26:592-598.

Tajima, S., M. Takahashi, S. N. Takeshima, S. Konnai, S. A. Yin, S Watarai, Y. Tanaka, M. Onuma, K. Okada, and Y. Aida. 2003. A mutant form of the tax protein of bovine leukemia virus (BLV), with enhanced transactivation activity, increases expression and propagation of BLV in vitro but not in vivo. J. Virol. 77:1894-1903.

USDA. 2007. Info sheet: bovine leukosis virus (BLV) on U.S. dairy operations. USDA Animal and Plant Health Services, Veterinary Services, Center for Epidemiology and Animal Health. Accessed Sep. 5, 2017. http://www.aphis.usda.gov/animal_health/nahms/ dairy/downloads/dairy07/Dairy07_is_BLV.pdf.

van Eijk, M. J., J. A. Stewart-Haynes, J. E. Beever, R. L. Fernando, and H. A. Lewin. 1992. Development of persistent lymphocytosis in cattle is closely associated with DRB2. Immunogenetics 37:64-68.

Ver Hoef, J. M., and P. L. Boveng. 2007. Quasi-Poisson vs. negative binomial regression: How should we model overdispersed count data? Ecology 88:2766-2772. 